\title{
Avaliação da carga de trabalho dos operadores de uma empresa distribuidora de derivados de petróleo
}

\author{
Lucimara Ballardin UFRGS \\ Lia Buarque de Macedo Guimarães UFRGS
}

\section{RESUMO}

Este artigo mostra o método adotado e os resultados obtidos em estudo realizado com operadores de uma distribuidora de derivados de petróleo da região Sul do Brasil. O objetivo era avaliar a carga de trabalho e os fatores que interferem nessa carga, do ponto de vista dos operadores. A metodologia aplicada incluiu entrevistas e dois questionários, um adaptado do NASA-TLX e um para levantamento dos fatores que interferem na carga de trabalho. Os resultados indicaram que a maioria dos operadores percebe que a carga de trabalho é alta. Entre os componentes da carga de trabalho, o desempenho é a que tem peso maior, enquanto os problemas relacionados a equipamentos e sistemas informatizados são os que mais influenciam nessa carga. Tendo em vista os resultados obtidos, é necessário aperfeiçoar os subsistemas, técnico e organizacional, da empresa para gerar melhorias na performance, saúde e satisfação dos operadores.

\section{Evaluation of an oil distributor company operator's workload}

\begin{abstract}
The aim of this study was to evaluate workloads as perceived by the operators of an oil distribution company in Southern Brazil. Workload levels were measured by a questionnaire adapted from the NASA-TLX, and the factors that impact on the workload were identified by interviews and questionnaire. The results showed that the workload level is high, mainly due to technical constraints (such as equipment and computational problems). Performance is the component which most influences workload. According to the results, it is necessary to improve the technical and organizational subsystems of the oil distribution company in order to improve human performance as well as the health and safety of the operators.
\end{abstract}

\section{KEYWORDS}

Workload, work conditions, oil distribution company. 


\section{INTRODUÇÃO}

A natureza do trabalho vem sofrendo modificações, embora estruturas e práticas antigas ainda sejam mantidas. A produção industrial está passando por um período de transição entre o modelo de organização da produção em massa (Taylorista-fordista) para um modelo de flexibilização, baseado nos princípios do Sistema Toyota de Produção. Nesse contexto, tornam-se constantes as exigências das organizações por aumento de produtividade e diminuição de custos, ao mesmo tempo em que são introduzidos novos conhecimentos e tecnologias para execução do trabalho. Essa mudança resulta em atividades que exigem dos trabalhadores competências como multifuncionalidade, autonomia, participação e interação com sistemas automatizados (HIRATA, 1993; WOMACK; JONES; ROOS, 1992).

Embora o trabalho tenha sido sempre formado por uma parcela mental, física e psíquica de carga de trabalho (WISNER, 1994), atualmente esses componentes também interagem com as exigências geradas pelos subsistemas humano, técnico, organizacional e do ambiente externo (HENDRICK, 1993). Dessa forma, ao trabalhador dos dias de hoje não é mais solicitada apenas a operação manual de máquinas, mas também a compreensão de sinais e a interpretação de dados (GUIMARÃES, 2004). Todas essas transformações resultam em novas formas para o homem de realizar, perceber e relacionar-se no seu trabalho (NEGRI; LAZZAROTO, 2001; NARDI; TITONI; BERNARDES, 1997).

\section{Aníveis inaceitáveis, também pode influenciar a ocorrência de acidentes (RASMUSSEN, 1997)}

Além dessas modificações na natureza do trabalho e, de forma geral, nas organizações, nas últimas décadas, em razão de políticas econômicas e estratégicas do país, a indústria petroquímica foi particularmente alterada pelo ambiente externo (CARDOSO, 2004). A concorrência imposta pela abertura do mercado brasileiro de comercialização de derivados de petróleo, a redução do número de trabalhadores e a automação dos processos são fatores que se tornaram frequentes (FERREIRA, 2002; CARRION, 1999). Como consequência, há indícios de que esses fatores estão gerando impactos na saúde e segurança dos trabalhadores que restam nessas empresas (DUARTE, 2002; ARAÚJO, 2001), pois estes tendem a lidar com o aumento das demandas e, consequentemente, da carga de trabalho.
A carga de trabalho é um fator organizacional que influencia diretamente o desempenho do homem no trabalho (SANDERS; MCCORMICK, 1993). Pela amplitude da sua significância, ela está entre as categorias definidas para avaliar o impacto produzido pelos elementos que constituem o processo de trabalho sobre a saúde física e mental dos trabalhadores (CORRÊA, 2003). Além de prejuízos à saúde, quando a carga de trabalho atinge níveis inaceitáveis também pode influenciar na ocorrência de acidentes durante o trabalho (RASMUSSEN, 1997). Considerando o período vivenciado por essas organizações e o fato de que as empresas que lidam com produtos inflamáveis requerem uma preocupação maior da sociedade em virtude da amplitude dos acidentes que podem proporcionar (GIL, 2000; SOUZA; FREITAS, 2002; FREITAS et al., 2001), surge a necessidade de avaliar as cargas de trabalho dos indivíduos que atuam nessas indústrias. Dentro desse contexto, este estudo procurou avaliar a carga de trabalho a que estão submetidos os operadores e os fatores que influenciam tal carga, por meio de um estudo de caso em uma distribuidora de derivados de petróleo.

\subsection{Definição de carga de trabalho}

Diferentes conceitos descrevem o termo carga de trabalho. De maneira geral, Wickens, Gordon e Liu (1998) entendem a carga de trabalho como a razão entre o tempo requerido e o tempo real disponível para a realização das tarefas. Outros autores como Moraes e Mont'Alvão (2000) citam que fatores relacionados ao ambiente físico e aos subsistemas técnico e humano geram a carga de trabalho. Já Hart (1982) apud Corrêa (2003) explica a carga de trabalho como a interação de fatores internos e externos ao trabalhador, resultando em uma experiência subjetiva. Para Diniz e Guimarães (2004), a carga de trabalho é o termo usado para descrever o efeito que a demanda tem sobre o trabalhador, em termos de esforço mental e físico, relacionando a quantidade de informação processada e o esforço empregado para que a tarefa seja desempenhada.

Embora tenham conceitos diferenciados, todos os autores parecem concordar que as tarefas (ou fatores ligados a ela) influenciam na geração da carga de trabalho. No entanto, é importante salientar que é uma avaliação sob o ponto de vista de quem executa a tarefa, e não da tarefa propriamente dita, uma vez que depende de características individuais (CORRÊA, 2003). Nesse caso, fatores que interferem na carga de trabalho, podendo aumentá-la ou diminuí-la, são o conhecimento do trabalhador e a sua experiência na atividade. Assim, é esperado que trabalhadores novatos 
tenham uma carga de trabalho mais elevada que os experientes, bem como espera-se que a fase de aprendizagem de novas tarefas exija uma carga de trabalho maior aos indivíduos do que as tarefas rotineiras (AMALBERTI, 1996).

A carga de trabalho pode ainda se manifestar nos trabalhadores como uma sobrecarga ou uma subcarga. A sobrecarga de trabalho corresponde a uma saturação do consumo de recursos, enquanto a subcarga é resultante da ausência de estímulos para a realização da tarefa. Ambas acarretam problemas para o ser humano na realização de seu trabalho (AMALBERTI, 1996). Assim, conhecendo os fatores intervenientes na carga de trabalho, é possível prevenir possíveis sobrecargas ou subcargas no trabalho de cada um.

\section{MÉTODO DE PESQUISA}

Do ponto de vista de sua natureza, trata-se de uma pesquisa aplicada, ou seja, tem por objetivo gerar novos conhecimentos que podem ser úteis à aplicação prática. De acordo com seus objetivos, é considerada uma pesquisa exploratória, que visa familiarizar-se com o problema estudado e então torná-lo mais explícito (GIL, 2006). Segundo a perspectiva de abordagem do problema, caracteriza-se como uma pesquisa quanti e qualitativa. Por sua vez, a sua apresentação é dada sob a forma de um estudo de caso uma investigação empírica que analisa um fenômeno contemporâneo dentro de seu contexto (YIN, 2001).

\subsection{Participantes da pesquisa}

O público-alvo deste estudo foi constituído pelos dezoito operadores que atuam diretamente na área operacional da empresa estudada (há vinte e um operadores na empresa, mas dois encontravam-se afastados do trabalho por motivo de doenças e um deles não aceitou participar do estudo). De forma geral, os operadores desempenham tarefas relacionadas ao carregamento e descarregamento de vagões-tanque, recepção e acompanhamento do carregamento realizado pelos motoristas de caminhões-tanque, recebimento de produtos (via dutos da refinaria e transporte rodoviário e ferroviário), mensuração de tanques e controle do volume de produto comercializado e armazenado.

\subsection{Local e período do estudo}

A empresa distribuidora estudada durante o primeiro semestre de 2006 é um terminal de distribuição de produtos derivados de petróleo, localizado na região metropolitana de Porto Alegre (RS).

Há no Rio Grande do Sul hoje três terminais de distribuição considerados primários, ou seja, aqueles que recebem o produto direto da refinaria e o distribuem para bases secundárias e compradores por atacado. $\mathrm{O}$ terminal estudado é a maior distribuidora de derivados de petróleo do sul do Brasil, tanto em volume comercializado como em extensão e número de clientes. É responsável pelo abastecimento das cidades do Rio Grande do Sul e de parte do estado de Santa Catarina. Além de esses fatores terem sido levados em consideração na escolha do local de estudo, o fato de existir um convênio entre o curso de Engenharia de Produção da Universidade Federal do Rio Grande do Sul e a empresa (2005-2007) favoreceu o acesso a ela.

\subsection{Instrumentos de pesquisa}

Para avaliar a carga de trabalho foram utilizados entrevistas e dois questionários: um adaptado por Diniz e Guimarães (2004) do instrumento NASA-TLX (National Aeronautics and Space Adiministration/Task Load) e um questionário de levantamento dos fatores que interferem na carga de trabalho. Por sua vez, a entrevista foi guiada por um roteiro semiestruturado e procurou compreender o trabalho dos operadores, bem como os resultados dos demais instrumentos de pesquisa. Esses instrumentos são descritos a seguir.

\subsubsection{Questionário adaptado do NASA-TLX}

Pode-se mensurar a carga de trabalho utilizando parâmetros fisiológicos ou subjetivos. Neste estudo, optou-se apenas por uma avaliação subjetiva, ou seja, o trabalhador responde um questionário considerando critérios de avaliação pessoal. Um dos métodos para medir subjetivamente a carga de trabalho é o instrumento NASA-TLX, originalmente proposto para avaliar a carga de trabalho mental (NASA, 1986). No entanto, os estudos de Diniz e Guimarães (2004) sugerem que esse instrumento não mensura apenas a carga mental, mas a carga de trabalho de modo geral, uma vez que considera vários fatores que provocam impacto no trabalho, inclusive a carga física.

Os fatores que compõem a carga de trabalho, de acordo com o NASA-TLX, são descritos na Tabela 1.

O questionário NASA-TLX foi adaptado e previamente validado por Guimarães e Diniz (2004). Esse instrumento resulta numa pontuação geral da carga de trabalho percebida pelos trabalhadores com base na mensuração de seis componentes distribuídos em seis subescalas e da escolha entre 15 combinações possíveis de pares. A versão original do questionário utiliza uma escala discreta Likert (NASA, 1986), diferente da versão adaptada por Diniz e Guimarães (2004), a qual consta de uma escala contínua de $15 \mathrm{~cm}$ proposta por Stone et al. (1974). 
Tabela 1: Componentes da carga de trabalho e suas definições, de acordo com o NASA-TLX.

\begin{tabular}{cl}
\hline Componentes da carga de trabalho & \multicolumn{1}{c}{ Definição } \\
\hline Demanda mental & Atividade mental requerida para a realização do trabalho. \\
Demanda física & Atividade física requerida para a realização do trabalho. \\
Demanda temporal & Pressão imposta na realização do trabalho, ou seja, para que se utilize o menor tempo possível em \\
& uma tarefa e/ou se faça mais tarefas no menor tempo. \\
Performance & Nível de satisfação com o desempenho pessoal na realização do trabalho. \\
Esforço & O quanto que se deve trabalhar, tanto no aspecto físico como mental, para se atingir um nível \\
desejado de desempenho. & \\
Nível de frustração & Fatores que inibem a realização do trabalho (por exemplo, insegurança, irritação, falta de estímulo, \\
& estresse, contrariedades, etc) ou influenciam a realização do trabalho.
\end{tabular}

\subsubsection{Procedimentos específicos}

Na aplicação do questionário adaptado do NASA-TLX, os trabalhadores escolheram, comparando os componentes par a par, quais aqueles que mais afetam a carga de trabalho. Em seguida, marcaram a intensidade de cada um dos fatores, de acordo com o modo como percebem a influência de tais fatores no seu trabalho.

Para compor a análise desse instrumento, inicialmente foram contabilizadas quantas vezes cada componente foi mencionado na escolha entre pares, o que caracteriza o peso de cada um dos componentes da carga de trabalho. $\mathrm{O}$ valor encontrado para cada um deles foi multiplicado pela sua respectiva intensidade marcada na escala contínua de $15 \mathrm{~cm}$. Os seis valores encontrados são analisados individualmente para compreender as diferenças e semelhanças dos componentes da carga de trabalho. A seguir, os resultados são somados para gerar a carga de trabalho. As pontuações apresentadas variam de 0 a 15 , sendo que valores acima de 7,5 correspondem a uma alta carga de trabalho, enquanto que os valores abaixo de 7,5 equivalem a baixo índice de carga de trabalho. Nessa etapa da análise, foi usado o software Excel. Também foi utilizado o software SPSS, por meio do qual foi calculado o coeficiente de correlação de Pearson, tanto entre os componentes da carga de trabalho como entre o valor total da carga de trabalho e o tempo de serviço dos trabalhadores. As hipóteses iniciais do estudo, baseadas em dados da literatura já descritos, levaram a crer que poderia existir alguma associação positiva entre a carga de trabalho e o tempo de serviço dos trabalhadores, bem como entre os componentes da carga de trabalho.

\subsubsection{Levantamento dos fatores que interferem na carga de trabalho}

Durante as aplicações iniciais do questionário adaptado NASA-TLX, os pesquisadores se perguntaram qual era o entendimento de cada um sobre o que essa ferramenta estava proporcionando naquela população, bem como quais fatores específicos estavam sendo considerados pelos trabalhadores em cada componente (ex: quais fatores interferem na demanda mental?). Para ter uma resposta, os pesquisadores optaram por incluir no estudo um instrumento complementar, elaborado e validado com o auxílio dos operadores. Assim, esse novo questionário passou a ser aplicado juntamente com o questionário de carga de trabalho.

O questionário de levantamento dos fatores que interferem na carga de trabalho era formado por duas colunas. $\mathrm{Na}$ primeira delas, foram listados os componentes da carga de trabalho, de acordo com a versão adaptada do NASA-TLX: demanda mental, demanda física, demanda temporal, performance, esforço e nível de frustração. Na segunda coluna, são enumerados os fatores específicos mencionados pelos trabalhadores nos testes preliminares, acrescidos de outras possibilidades sugeridas pelos pesquisadores, totalizando 26 itens. Foram reservados dois espaços para que o trabalhador pudesse acrescentar no momento do seu preenchimento novos fatores não previstos inicialmente.

\subsubsection{Procedimentos específicos}

Durante a aplicação do questionário de levantamento dos fatores que interferem na carga de trabalho os trabalhadores justificaram as razões pelas quais haviam marcado suas respostas no primeiro questionário (versão adaptada NASA-TLX). A partir de então, foram orientados a preencher cada fator associado a cada componente da carga de trabalho. Também foram avisados quanto à possibilidade de repetir um fator mais de uma vez, bem como o fato de que não havia necessidade de classificar todos os fatores listados.

A análise dos resultados foi realizada por meio da frequência das respostas, enquanto a interpretação deles foi conduzida qualitativamente. A seguir, os fatores listados foram classificados de acordo com a visão da ergonomia nos constructos técnico, humano, organizacional e ambiental (GUIMARÃES, 2004). 


\subsection{Procedimentos gerais de pesquisa}

Antes da aplicação dos instrumentos houve, impreterivelmente, uma explicação a cada um sobre os objetivos e procedimentos da pesquisa. Todos os participantes manifestaram sua concordância por meio de assinatura do Termo de Consentimento Livre e Esclarecido, de acordo com a Resolução nº 196 do Conselho Nacional de Saúde.

\section{RESULTADOS E DISCUSSÕES}

Os dados sociodemográficos da população estudada são apresentados na Tabela 2. Dos operadores que participaram do estudo, 16 são homens e duas são mulheres, apresentam faixa etária entre 26 e 62 anos e tempo de serviço que varia de 4,58 a 29 anos. Esses trabalhadores ingressaram na empresa via concurso público. Todos têm ensino médio (escolaridade mínima exigida pela empresa) e nenhum concluiu o ensino superior.

\subsection{Resultados do questionário adaptado do NASA-TLX}

A figura 1 apresenta o resultado geral do questionário adaptado do NASA-TLX, discriminado para cada participante. Para interpretação dos resultados, foi considerado que, quanto mais próximo da pontuação 15 , maior a carga

Tabela 2: Dados sociodemográficos dos participantes do estudo.

\begin{tabular}{|c|c|c|c|}
\hline Operador & Idade* & $\begin{array}{l}\text { Tempo de } \\
\text { serviço* }\end{array}$ & Sexo \\
\hline 1 & 62 & 11 & masculino \\
\hline 2 & 54 & 11 & masculino \\
\hline 3 & 42 & 16 & masculino \\
\hline 4 & 48 & 29 & masculino \\
\hline 5 & 53 & 27 & masculino \\
\hline 6 & 30 & 4,58 & feminino \\
\hline 7 & 30 & 4,75 & masculino \\
\hline 8 & 48 & 7 & masculino \\
\hline 9 & 26 & 4,83 & masculino \\
\hline 10 & 40 & 6 & masculino \\
\hline 11 & 44 & 16 & masculino \\
\hline 12 & 48 & 19 & masculino \\
\hline 13 & 41 & 17 & masculino \\
\hline 14 & 48 & 26 & masculino \\
\hline 15 & 45 & 19 & masculino \\
\hline 16 & 37 & 5 & feminino \\
\hline 17 & 53 & 25 & masculino \\
\hline 18 & 41 & 10 & masculino \\
\hline Mediana & 44,5 & 13,5 & \\
\hline
\end{tabular}

* em anos de trabalho. Assim, foi estabelecido que valores até 7,5 representam cargas de trabalho admissíveis, enquanto valores acima de 7,5 equivalem a alta carga de trabalho. Portanto, a análise da figura 1 mostra que, dos dezoito operadores que responderam ao questionário, apenas um apresentou valor 7,4, ou seja, inferior a 7,5. Esse operador é do sexo feminino e tem pouco tempo de serviço quando comparado aos outros trabalhadores (5 anos). Todos os demais operadores apresentaram carga de trabalho maior que 8,1 . De acordo com esses resultados, constata-se que $94,44 \%$ apresentaram escores elevados de carga de trabalho.

A distribuição dos resultados sugere um comportamento simétrico do grupo, ou seja, não há participantes com comportamento atípico à avaliação. A simetria dos dados é percebida pela similaridade entre o valor da mediana $(10,29)$ e da média $(10,25)$. Portanto, é possível afirmar que os valores dos indivíduos quanto à percepção da carga estão em torno de 10,25. Esta distribuição simétrica sugere que as causas de tais resultados devem estar ligadas principalmente às condições de trabalho (Tabela 3 ).

No entanto, é fato que a carga de trabalho também pode sofrer influência das características pessoais de cada operador. Elas podem estar relacionadas a diferenças na combinação de experiências, habilidade, estados emocionais, motivação, estimativa do risco e a percepção do custo de uma tarefa (CORRÊA, 2003). Na figura 2 é ilustrado como o total da carga de trabalho de cada indivíduo é composto. A análise da figura gráfica mostra que, embora quase todos os operadores apresentem uma pontuação acima de 7,5, essa carga de trabalho possui composições diferenciadas. Por exemplo, enquanto para alguns a demanda mental é o componente que representa a maior parte da composição da carga de trabalho, para outros é a demanda física. Notase também que para alguns operadores a carga de trabalho

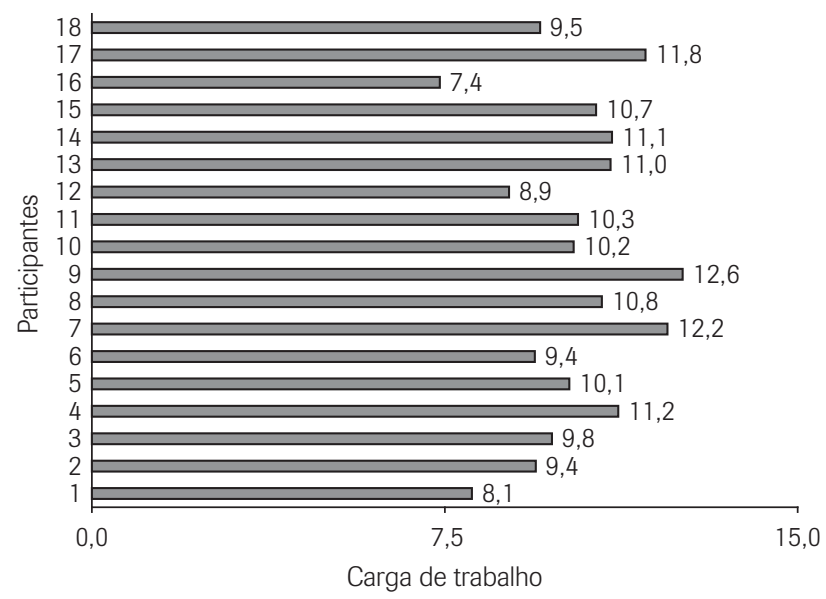

Figura 1: Resultados da carga de trabalho por participante. 
Tabela 3: Resumo estatístico da variável carga de trabalho.

\begin{tabular}{cccccccc}
\hline \multirow{2}{*}{ Variável } & Mínimo & Máximo & \multicolumn{3}{c}{ Quartis } & Média & Desvio-padrão \\
\cline { 4 - 6 } & & & $25 \%$ & $50 \%$ & $75 \%$ & 10,25 & 1,35 \\
\hline Carga de trabalho & 7,39 & 12,56 & 9,43 & 10,29 & 11,09 & 109 \\
\hline
\end{tabular}

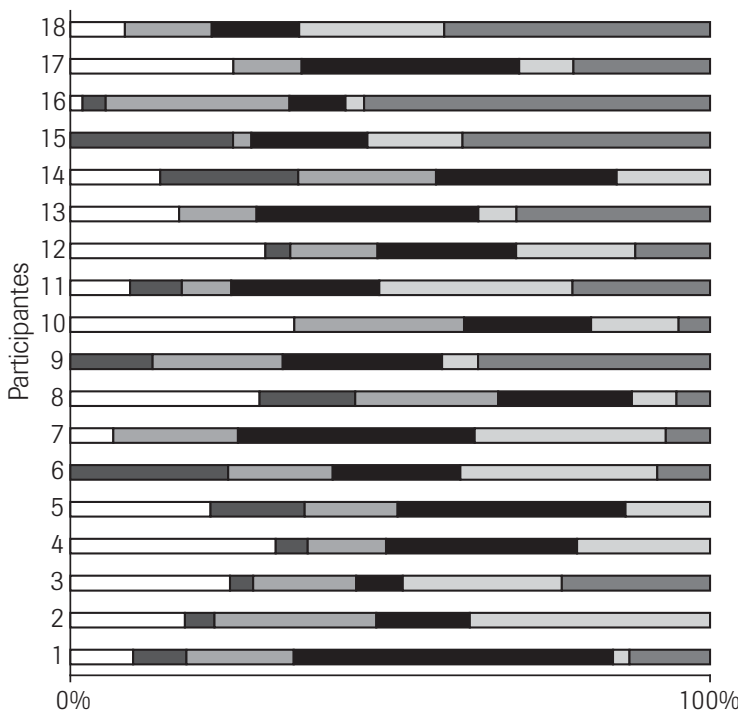

$\square$ Demanda mental
$\square$ Demanda física
$\square$ Demanda temporal
$\square$ Performance
$\square$ Esforço (físico e mental)
$\square$ Nível de frustração

Figura 2: Composição da carga de trabalho por participante.

está dividida em um número menor de componentes. Isso pode ser percebido quando se analisam os resultados dos operadores de número 9, 6 e 15, para os quais a percepção da carga de trabalho se divide em apenas cinco componentes. Esses operadores não percebem a demanda mental como parcela da carga de trabalho. No entanto, não foi possível encontrar um padrão que justificasse tais resultados em relação aos dados sociodemográficos.

Quanto aos componentes da carga de trabalho, a análise das medianas aponta que, em uma escala de 0 a 5 , os operadores possuem escores de performance $(2,33)$ mais elevados que os demais componentes (figura 3 ). Por sua vez, a demanda física $(0,5)$ é o componente que, no geral, representa para os trabalhadores a proporção menor da carga de trabalho. Assim, é possível afirmar que, embora o trabalho seja operacional e, por isso, tenha muitos aspectos físicos

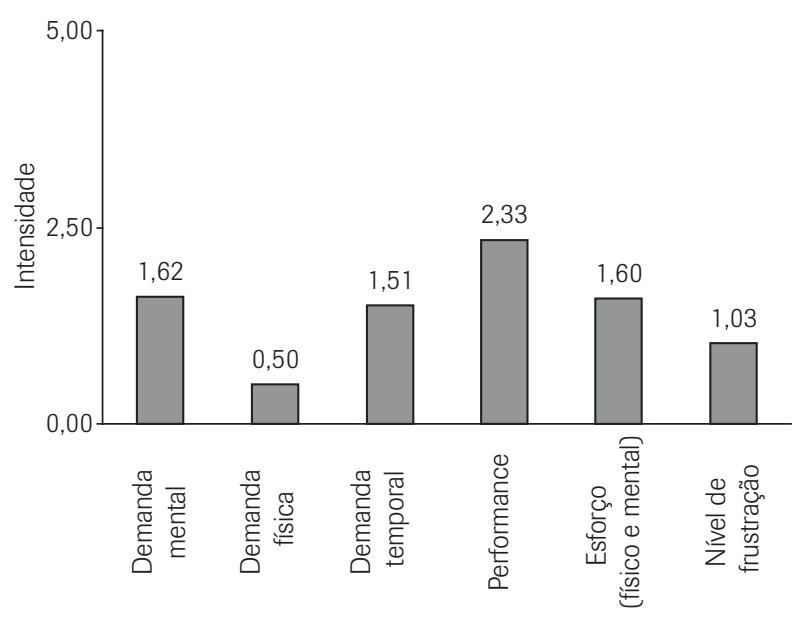

Figura 3: Mediana dos componentes da carga de trabalho.

envolvidos, as demandas físicas têm menor peso na carga de trabalho do que a demanda mental.

A Tabela 4 complementa a análise com os resultados do coeficiente de correlação de Pearson entre os componentes. Os resultados apontam que apenas a demanda mental e o nível de frustração apresentam um valor de correlação moderado $(-0,54)$, ou seja, há indícios de que quanto maior a demanda mental, menor o nível de frustração, e vice-versa. Esse resultado mostra que, embora as modificações no mundo do trabalho tenham aumentado as exigências cognitivas dos trabalhadores (GUIMARÃES, 2004; WISNER, 1994), para a empresa estudada o crescimento da demanda mental parece contribuir para diminuir o nível de frustração dos operadores. Portanto, parece que esse aumento representa a valorização dos operadores, bem como implica em maior satisfação no trabalho. Esse resultado está de acordo com as afirmações de que os trabalhos monótonos, repetitivos e que, consequentemente, requerem menor demanda mental, causam insatisfação (GRADJEAN, 1998). Também reforça os pressupostos de que a separação do trabalho físico do mental, proposta pelo Taylorismofordismo, implica em prejuízos à saúde física e mental dos trabalhadores (DEJOURS, 1995; NARDI; TITONI; BERNARDES, 1997).

Segundo Amalberti (1996), a aprendizagem de novas tarefas impõe uma carga de trabalho maior aos trabalhadores 
Tabela 4: Cálculo do coeficiente de correlação de Pearson entre as componentes da carga de trabalho.

\begin{tabular}{lcccccc}
\hline & Demanda mental & Demanda física & $\begin{array}{c}\text { Demanda } \\
\text { temporal }\end{array}$ & Performance & $\begin{array}{c}\text { Esforço } \\
\text { Nível de } \\
\text { frustração }\end{array}$ \\
\hline Demanda mental & 1 & $-0,38$ & 0,15 & 0,12 & $-0,05$ & $-0,54$ \\
Demanda física & $-0,38$ & 1 & $-0,2$ & $-0,03$ & $-0,05$ & $-0,06$ \\
Demanda temporal & 0,15 & $-0,12$ & 1 & $-0,01$ & $-0,04$ & $-0,31$ \\
Performance & 0,12 & $-0,03$ & $-0,01$ & 1 & $-0,14$ & $-0,24$ \\
Esforço & $-0,05$ & $-0,05$ & $-0,04$ & $-0,24$ & $-0,35$ & $-0,35$ \\
Nível de frustração & $-0,54$ & $-0,06$ & $-0,31$ & & & 1 \\
\hline
\end{tabular}

do que a execução de tarefas rotineiras. Por isso, era esperado que operadores novatos apresentassem uma carga de trabalho mais elevada do que os experientes. O coeficiente de correlação de Pearson entre a carga total de trabalho e o tempo de serviço dos funcionários é de 0,2 . Sendo assim, o valor encontrado é baixo, apesar de positivo. De outra forma, pode-se dizer que há indícios (embora leves e com necessidade de investigação adicional) de que nessa empresa quanto maior o tempo de serviço, maior a carga de trabalho. Esses resultados podem decorrer do fato de tratar-se de uma empresa pública, o que pode tê-los influenciado a se diferenciarem da literatura pertinente. O tipo de emprego concedido por empresas assim caracteriza-se por uma relativa estabilidade profissional. No entanto, com o passar dos anos, a burocratização e a dificuldade de ascensão profissional, relatados pelos operadores nas entrevistas, passam a exercer influência e aumentam a carga de trabalho. Da mesma forma, é importante ressaltar que, nessa empresa, o menor tempo de serviço é de quatro anos, o que também pode ter influenciado os resultados, já que não pode ser caracterizado como curto quando comparado com as empresas privadas.

\subsection{Questionário de avaliação dos fatores que interferem na carga de trabalho}

Para compreender melhor os resultados da carga de trabalho, os fatores que interferem em cada componente da carga - ou seja, aqueles responsáveis pela inibição da realização do trabalho foram especificados pelos operadores. Com isso, foi possível contextualizar a percepção dos operadores com base em situações específicas de seu trabalho e verificar o entendimento próprio dos conceitos. Todos os resultados são apresentados de acordo com a frequência de escolha dos operadores, justificada nas entrevistas.

\subsubsection{Demanda mental}

A análise dos fatores geradores da demanda mental, conforme figura 4 , sugere que ela é afetada, em maior proporção, pela pressão $(50 \%)$ e pelo relacionamento com clientes (motoristas) (41,67\%). Nesse caso, observa-se que esses fatores estão relacionados mais com aspectos psíquicos do que com processamento de informação propriamente dito (WISNER, 1994). Por sua vez, as exigências de atenção $(41,67 \%)$ e, consequentemente, o cansaço mental $(41,67 \%)$ foram relacionados nas entrevistas ao risco do produto e a irreversibilidade de alguns processos, tais como a atividade de abertura de válvulas erradas.

\subsubsection{Demanda física}

As horas extras (58,33\%) e as posturas exigidas para a realização das atividades $(58,33 \%)$ são os fatores que mais influenciaram a demanda física (figura 5). O cansaço físico $(41,67 \%)$, a quantidade de trabalho $(33,33 \%)$ e os problemas com equipamentos e sistemas $(33,33 \%)$ também foram levados em consideração quando os operadores avaliaram esse componente da carga.

Embora as horas extras constituam um fator organizacional e estejam diretamente relacionadas com a quantidade de trabalho, é interessante observar que esse fator é ressaltado para justificar apenas a demanda física. As horas extras são habituais entre os operadores em virtude da quantidade de tarefas que devem ser desempenhadas e das intercorrências que prejudicam a sua execução durante a jornada de trabalho. Já a quantidade de trabalho é um fator considerado gerador tanto de demanda física como temporal (apresentada a seguir). Muitos operadores justificam este fator relacionando-o com a má distribuição de tarefas entre os trabalhadores, o que, possivelmente, faz com que a quantidade de trabalho seja maior para alguns.

Além de escolhidos pelos operadores para explicar a demanda física, os problemas no sistema e equipamentos também são mencionados como geradores de demanda temporal, do esforço e do nível de frustração. Esse fator é responsável tanto por interromper o carregamento dos caminhões-tanque, o que causa reclamações por parte dos motoristas, como por gerar horas extras. Sem o auxílio dos equipamentos, os operadores devem improvisar alguns 


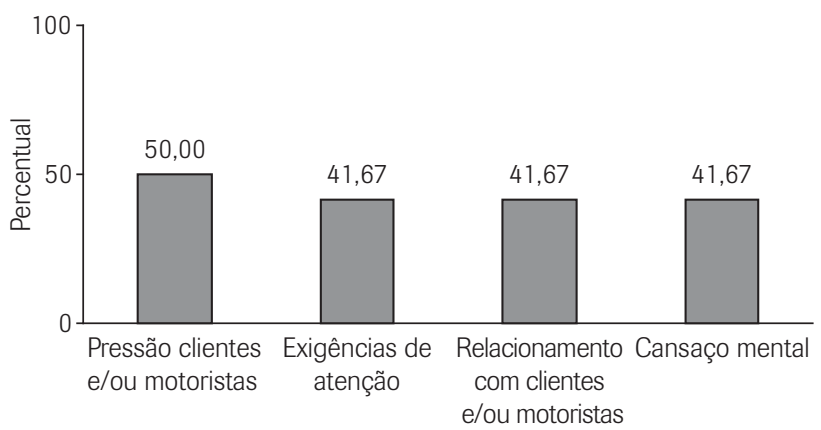

Figura 4: Fatores que interferem na demanda mental.

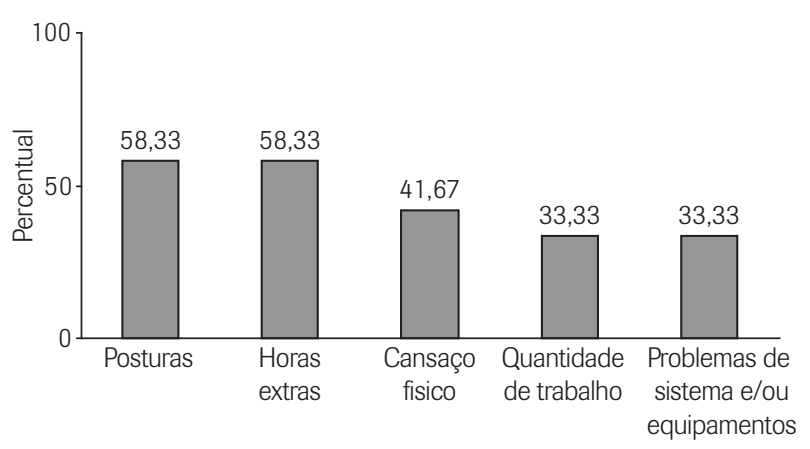

Figura 5: Fatores que interferem na demanda física.

procedimentos que podem ser realizados manualmente. Depois que o problema é resolvido, o trabalho deve ser intensificado para compensar o atraso das atividades.

\subsubsection{Demanda temporal}

A figura 6 mostra que, além dos problemas no sistema e/ou equipamentos $(41,67 \%)$ e a quantidade de trabalho (41,67\%) - já descritos juntamente com a demanda física -, a demanda temporal é influenciada pela pressão exercida pelos colegas $(41,67 \%)$ e pelas condições climáticas adversas $(33,33 \%)$.

A pressão exercida pelos colegas é justificada pelo fato de que algumas tarefas só podem ser desempenhadas após a realização de outra, a qual muitas vezes encontra-se sob responsabilidade de outro operador. Um exemplo é a mensuração de tanques, tarefa que requer que todas as transferências de produtos realizadas pelo setor de recebimento sejam concluídas para que os tanques sejam novamente mensurados e, consequentemente, suas atividades possam ser encerradas. Outro exemplo é o grau de dependência entre o setor onde os caminhões são vistoriados e a portaria, os quais necessitam de interação constante para que a saída dos caminhões seja efetuada adequadamente.

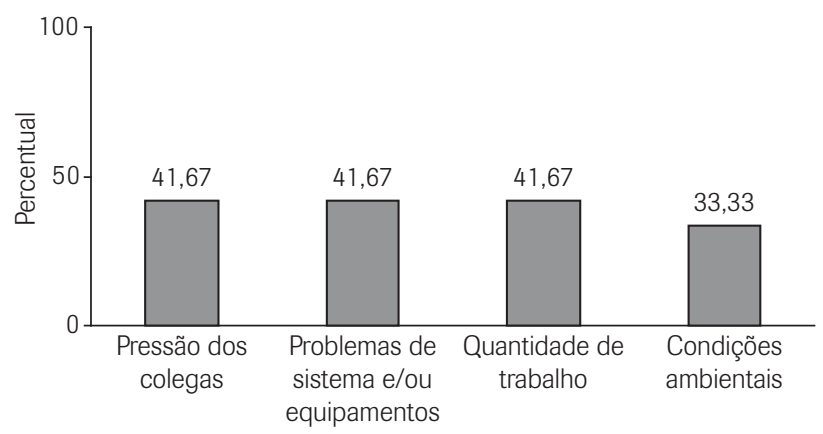

Figura 6: Fatores que interferem na demanda temporal.

Por sua vez, as condições climáticas interferem diretamente no conforto e na eficiência das atividades desempenhadas, uma vez que a área operacional apresenta poucos ambientes com cobertura e/ou proteções contra condições climáticas adversas, tais como chuva, sol e temperaturas extremas. Os operadores mencionaram a dificuldade para registrar mensurações dos tanques, já que elas são realizadas a céu aberto, utilizando caneta e folhas de papel. Também foi salientado que, em dias chuvosos, os operadores se sentem mais vulneráveis a sofrer acidentes do tipo queda.

\subsubsection{Performance}

Como já ressaltado, a performance é o componente de maior peso na carga de trabalho. Os fatores que dão origem a esse resultado são apresentados na Figura 7.

O cansaço físico $(41,67 \%)$ e os resultados no trabalho $(41,67 \%)$ são fatores que interferem de forma mais intensa na performance. Como a maior parte das atividades operacionais requer deslocamento entre setores, subida de escadas e posturas em pé, o desempenho dos operadores depende também de sua integridade física. Por essa razão, os operadores que têm algum tipo de problema físico são alocados na portaria, pois é a única tarefa que possibilita a postura sentada durante toda a jornada de trabalho. Atualmente, dois operadores são alocados prioritariamente na portaria e, por isso, reclamam que o reconhecimento profissional por parte de seus pares é prejudicado pelas limitações físicas. Da mesma forma acreditam que sejam vistos pelos demais como limitadores do desempenho do grupo e, consequentemente, uma fonte de sobrecarga de trabalho para os demais operadores. Segundo Dejours (1995), o não reconhecimento dos pares é fonte de sofrimento psíquico entre os trabalhadores, o que compromete sua saúde mental.

Como para os operadores os resultados do trabalho também são determinantes da performance, parece lógico 


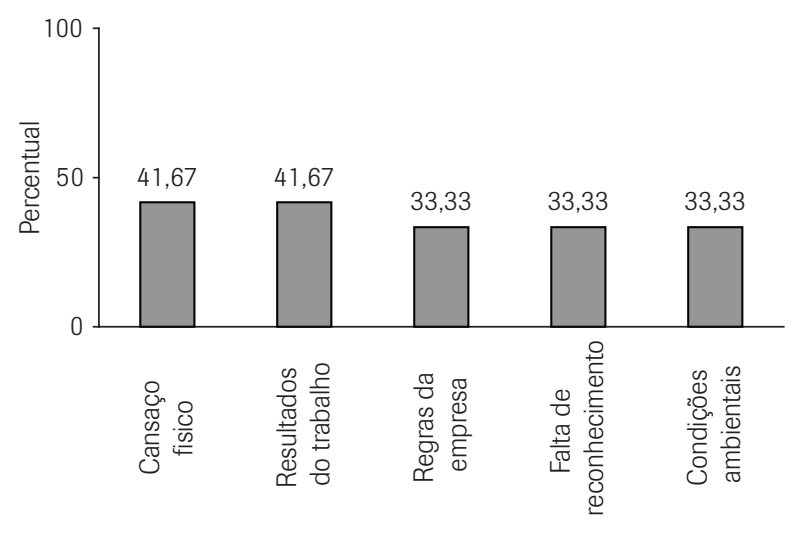

Figura 7: Fatores que interferem na performance.

associar a relação entre desempenho e resultados, ou seja, a idéia de que um bom desempenho gera bons resultados. As regras da empresa (33,33\%) também afetam a performance, ou seja, tanto é possível garantir o desempenho devido às regras, bem como ele pode ser limitado por elas. Exemplos dessa situação puderam ser percebidos durante as entrevistas, nas quais alguns operadores mencionaram sugestões que já haviam sido dadas à gerência para otimizar o trabalho. No entanto, embora acreditem que suas soluções sejam viáveis, eles são conscientes de que, quando tais sugestões são levadas a seus superiores, elas não são colocadas em prática em virtude do caráter burocrático da empresa.

A falta de reconhecimento (33,33\%) também é apontada nesse componente da carga de trabalho. Segundo alguns entrevistados, a empresa não reconhece quando todas as metas são atingidas, mas, quando erram, são chamados a explicar-se. Nesse caso, a falta de reconhecimento também pode estar sendo um fator limitador, ou seja, ela pode estar afetando negativamente a performance. Alguns operadores ainda se referem à jornada de trabalho como "uma rotina de batalha diária" que, com muito esforço, necessitam vencer para não comprometer a viabilidade da empresa.

\subsubsection{Esforço}

Durante a aplicação do questionário adaptado NASA-TLX, o esforço foi o componente da carga de trabalho que mais gerou dúvidas quanto a sua definição. Constantemente, os pesquisadores foram solicitados a diferenciar o esforço das demandas físicas e mentais. Portanto, a interpretação dos operadores corresponde aos fatores que foram considerados por eles, de acordo com a figura 8. Eles priorizaram o cansaço mental (50\%) e, em menor proporção, o cansaço físico $(41,67 \%)$, a pres-

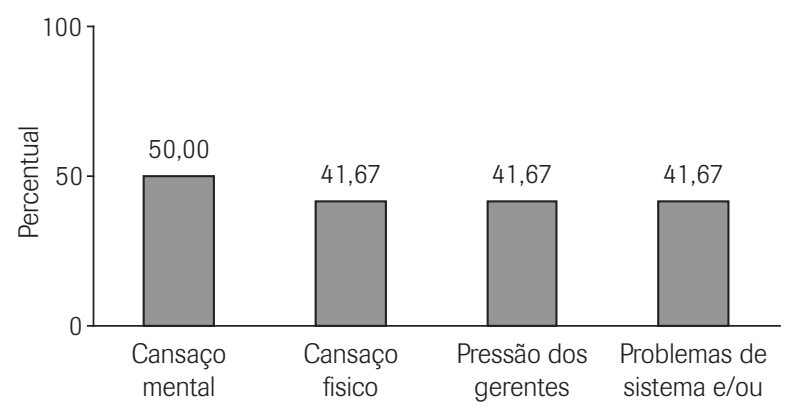

Figura 8: Fatores que interferem no esforço.

são dos gerentes $(41,67 \%)$ e os problemas com o sistema e equipamentos $(41,67 \%)$.

Os resultados apontam que, embora o trabalho tenha exigências físicas, as exigências mentais se sobressaem ou causam mais impacto em termos de esforço dos operadores. As razões podem estar ligadas à constante atenção durante a atividade, ao risco oferecido pelo produto manipulado e também à interação dos sistemas humano e técnico. Essa suposta incompatibilidade entre os operadores e a tecnologia adotada, seja sob a forma da recente automatização do sistema ou a quantidade de identificações em inglês do sistema informatizado e dos medidores de carregamento rodoviário, é um fator que pode não estar compatível, inclusive, com o nível de escolaridade e capacitação dos operadores. Durante as entrevistas, todos eles mencionaram não compreender a língua inglesa.

O fator citado exclusivamente para explicar o esforço é a pressão dos gerentes. Assim, o esforço que o trabalho requer dos operadores é influenciado pelas pressões gerenciais. Esse resultado, no entanto, não foi relacionado com a performance. Assim, percebe-se que a pressão gerencial é determinante do esforço que os operadores realizam, mas não necessariamente influenciam o desempenho deles durante a execução das atividades. Em seguida, novamente são citados os problemas com equipamentos e sistemas computacionais, já que falhas requerem a compensação do trabalho automatizado, seja sob a forma de horas extras, trabalho manual ou intensificação do ritmo de trabalho.

\subsubsection{Nível de frustração}

A maior parte dos operadores considera a falta de reconhecimento $(58,33 \%)$ como um dos principais fatores que inibem a realização no trabalho, ou seja, contribuem para caracterizar o seu nível de frustração (Figura 9). Esse fator também foi citado durante as entrevistas, quando os operadores comentaram que apenas recebem feedback de seus superiores quando cometem erros. Alguns trabalhadores 
também acreditam que o fato de se destacar no grupo resulta apenas em mais trabalho em relação aos demais colegas, pois bom desempenho e habilidades não parecem, para eles, quesitos utilizados para proporcionar ascensão profissional (50\%). De acordo com a percepção dos operadores, a política de recursos humanos da empresa também não proporciona remuneração e incentivos (50\%) suficientes, o que também parece frustrá-los.

Os problemas com sistema e/ou equipamentos (50\%) novamente são lembrados como fatores que geram frustração, do mesmo modo que interferem nas demandas mental, física e temporal e no esforço. Esse tipo de problema pode, efetivamente, provocar redução do trabalho em determinado período de tempo.

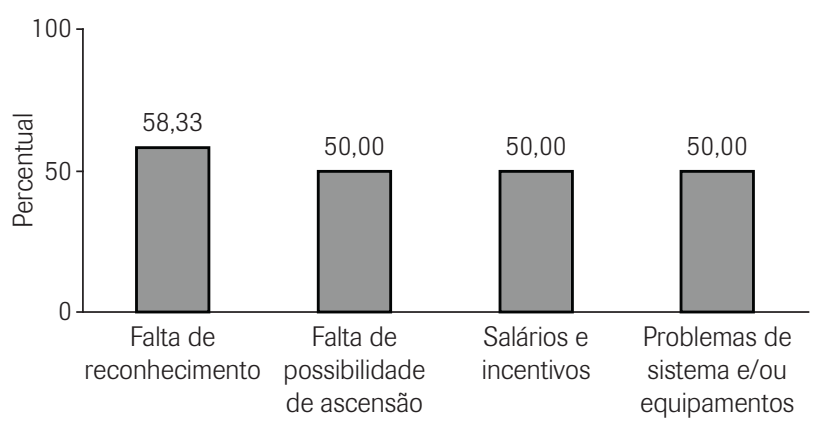

Figura 9: Fatores que interferem no nível de frustração.

\subsubsection{Classificicação dos fatores levantados}

Buscando compreender melhor suas origens, os fatores que interferem em cada componente da carga de trabalho foram classificados nos constructos técnico, humano, organizacional e do ambiente (Tabela 5), conforme enfoque da Ergonomia.

É possível observar que os fatores relacionados ao constructo organizacional interferem em todos os componentes da carga de trabalho. Ele apresenta principalmente problemas relacionados à falta de reconhecimento e quantidade de trabalho. Também está no constructo organizacional a maior diversidade de fatores citados, enquanto que as menores estão no constructo técnico e ambiental (apenas um fator foi levantado). Os fatores relacionados ao constructo técnico concentram os problemas de sistemas informatizados e equipamentos da empresa, reforçando a hipótese previamente levantada sobre possível incompatibilidade humano-sistema. Por sua vez, o constructo ambiental apenas apresenta fatores relacionados às condições climáticas, o que parece óbvio em um parque industrial praticamente a céu aberto. No constructo humano, há predomínio do cansaço mental e físico. Nesse caso, embora estes e os demais fatores citados nesse constructo sejam geradores de demandas ao ser humano, suas causas estão na configuração do trabalho, o que reforça os fatores ligados aos constructos técnico e organizacional.

Tabela 5: Resumo dos fatores que interferem na carga de trabalho, de acordo com o constructo envolvido.

\section{Constructos}

$\begin{array}{lll}\text { Humano Técnico/máquina } & \text { Organizacional } & \\ & & \text { Ambiente físico }\end{array}$

\begin{tabular}{|c|c|c|c|c|}
\hline \multirow[t]{2}{*}{ Demanda mental } & Exigências de atenção & & $\begin{array}{c}\text { Pressão clientes e/ou } \\
\text { motoristas }\end{array}$ & \\
\hline & Cansaço mental & & $\begin{array}{c}\text { Relacionamento com clientes } \\
\text { e/ou motoristas }\end{array}$ & \\
\hline \multirow[t]{2}{*}{ Demanda física } & Posturas & \multirow{2}{*}{$\begin{array}{c}\text { Problemas de sistemas e } \\
\text { equipamentos }\end{array}$} & Quantidade de trabalho & \\
\hline & Cansaço físico & & Horas extras & \\
\hline \multirow{2}{*}{$\begin{array}{l}\text { Demanda } \\
\text { temporal }\end{array}$} & & \multirow{2}{*}{$\begin{array}{l}\text { Problemas de sistemas e } \\
\text { equipamentos }\end{array}$} & Quantidade de trabalho & Condições climáticas \\
\hline & & & Pressão dos colegas & \\
\hline \multirow[t]{3}{*}{ Performance } & \multirow[t]{3}{*}{ Cansaço físico } & & Regras da empresa & Condições climáticas \\
\hline & & & Resultados do trabalho & \\
\hline & & & Falta de reconhecimento & \\
\hline \multirow[t]{2}{*}{ Esforço } & Cansaço mental & \multirow{2}{*}{$\begin{array}{c}\text { Problemas de sistemas e } \\
\text { equipamentos }\end{array}$} & \multirow[t]{2}{*}{ Pressão dos gerentes } & \\
\hline & Cansaço físico & & & \\
\hline \multirow{3}{*}{$\begin{array}{l}\text { Nível de } \\
\text { frustração }\end{array}$} & & \multirow{3}{*}{$\begin{array}{c}\text { Problemas de sistemas e } \\
\text { equipamentos }\end{array}$} & Salários e incentivos & \\
\hline & & & $\begin{array}{l}\text { Falta de possibilidade de } \\
\text { ascensão profissional }\end{array}$ & \\
\hline & & & Falta de reconhecimento & \\
\hline
\end{tabular}




\section{CONCLUSÕES}

Este trabalho teve por objetivo avaliar a carga de trabalho dos operadores e os fatores que a influenciam, por meio de um estudo de caso em uma distribuidora de derivados de petróleo. De acordo com os resultados, a carga de trabalho da maior parte dos trabalhadores apresentou pontuações elevadas. Entre os seis componentes da carga de trabalho, a que apresentou maior peso foi a performance. Conforme a avaliação dos operadores, os fatores que contribuem para o aumento de tal carga estão no próprio contexto da organização do trabalho. $O$ fator que parece influenciar o maior número de componentes da carga de trabalho - causa impacto simultaneamente nas demandas física e temporal, esforço e nível de frustração - são os problemas relacionados aos equipamentos e ao sistema informatizado. $\mathrm{O}$ método participativo, utilizado neste estudo, permitiu esclarecer as percepções dos trabalhadores no contexto de uma visão sistêmica da empresa. E a mesma ferramenta de participação que conduziu ao diagnóstico também pode auxiliar a empresa na busca das soluções de melhorias (sabe-se que atualmente a empresa possui um número maior de operadores do que o da época do estudo).

Embora tenha se limitado a um estudo de caso, é possível que demais subsidiárias desta companhia enfrentem situações parecidas, principalmente porque os problemas levantados também estão ligados a fatores organizacionais e técnicos. Da mesma forma, resultados similares podem ser encontrados em outras empresas do mesmo ramo. No entanto, tais sugestões necessitam de evidências, as quais podem ser corroboradas apenas com a realização de novos estudos. Comparar os resultados com outros estudos em distribuidoras multinacionais também poderia evidenciar mais claramente as peculiaridades inerentes ao processo de reestruturação produtiva, bem como o modelo de gestão de uma empresa pública de capital exclusivamente brasileiro.

\section{Artigo recebido em 25/06/2007 Aprovado para publicação em 28/06/2009}

\section{REFERÊNCIAS}

AMALBERTI, R. La conduite de systèmes à risques. Paris: Universitaires de France, 1996.

ARAÚJO, A. Paradoxos da modernização: terceirização e segurança dos trabalhadores em uma refinaria de petróleo. Rio de Janeiro, 2001. Tese (Doutorado em Saúde Coletiva) - Fundação Oswaldo Cruz - Fiocruz.

CARDOSO, L. C S. Logística do petróleo: transporte e armazenamento. Rio de Janeiro: Interciência, 2004.

CORRÊA, F. P. Carga mental e ergonomia. Florianópolis, 2003. Dissertação (Mestrado em Engenharia de Produção) - Universidade Federal de Santa Catarina - UFSC.

DEJOURS, C. Psicodinâmica do trabalho: contribuições da escola dejouriana à análise da relação prazer, sofrimento e trabalho. São Paulo: Atlas, 1995.

DINIZ, R. L.; GUIMARÃES, L. B. M. Avaliação da carga de trabalho mental. In: GUIMARÃES, L. B. M. Ergonomia cognitiva. Porto Alegre: FEENG, 2004.
FERREIRA, L. A intensificação do trabalho ou "É proibido vacilar". In: DUARTE, F. Ergonomia e projeto na indústria de processo contínuo. Rio de Janeiro: Lucerna, 2002.

FREITAS, C. M. et al. Acidentes de trabalho em plataformas de petróleo da Bacia de Campos, Rio de Janeiro, Brasil. Cadernos de Saúde Pública, v. 17, n. 1, p. 117-130, 2001.

GIL, T. B. Impactos da reestruturação produtiva à saúde e à segurança: percepções de petroleiros em São Paulo. Campinas, 2000. Dissertação (Mestrado em Sociologia) - Universidade Estadual de Campinas - UNICAMP, 2000.

GIL, A. C. Métodos e técnicos de pesquisa social. São Paulo: Atlas, 2006.

GUIMARÃES, L. B. M. Ergonomia cognitiva. Porto Alegre: FEENG, 2004.

HENDRICK, H. W. Macroergonomics: a new approach for improving productivity, safety and quality of work life. In: CONGRESSO LATINOAMERICANO DE ERGONOMIA E SEMINÁRIO BRASILEIRO DE ERGONOMIA, 6, 1993. Anais...
HIRATA, H. Sobre o modelo japonês. São Paulo: EDUSP, 1993.

MORAES, A.; MONT'ALVÃO, C. R. Ergonomia: conceitos e aplicações. 2 ed. São Paulo: 2AB, 2000.

NARDI, H.; TITONI, J.; BERNARDES, J. Subjetividade e trabalho. In: CATTANI, A. D. (Org.). Trabalho e tecnologia: dicionário crítico. Porto Alegre: Vozes, 1997.

NASA. Task Load Index (TLX): computerized version (Version 1). Califórnia: Human Research Performance Group, 1986.

NEGRI, A.; LAZZAROTO, M. Trabalho imaterial: formas de vida e produção de subjetividade. Rio de Janeiro: DP\&A, 2001.

RASMUSSEN, J. Risk management in a dynamic society: a modeling problem. Safety Science, v. 27, n. 2-3, p. 183-213, 1997.

SANDERS, M. S.; MCCORMICK, E. J. Human factors in engineering and design. New York: McGraw-Hill, 1993. 
SOUZA, C. A. V.; FREITAS, C. M. Perfil dos acidentes de trabalho em refinaria de petróleo. Revista de Saúde Pública, v. 36, n. 5, p. 576-583, 2002.

STONE, H. et al. Sensory evaluation by quantitative descriptive analysis. Food Technology, v. 28, n. 1, p. 24-34, 1974.
YIN, R. K. Estudo de caso: planejamento e métodos. Porto Alegre: Bookman, 2001.

WICKENS, C.; GORDON, S; LIU, Y. An introduction to human factors enginnering. New York: Longman, 1998.
WISNER, A. A inteligência no trabalho: textos selecionados de ergonomia. São Paulo: Fundacentro, 1994.

WOMACK, J.; JONES, D.; ROOS, D. A máquina que mudou o mundo. Rio de Janeiro: Campus, 1992.

\section{AGRADECIMENTOS}

Os autores agradecem a TENOAS/BR Distribuidora por permitir a realização deste estudo e autorizar a divulgação dos dados, inclusive com a identificação da empresa.

\section{SOBRE OS AUTORES}

Lucimara Ballardin

Universidade Federal do Rio Grande do Sul - UFRGS

Porto Alegre, RS, Brasil

E-mail: luciballardin@yahoo.com.br

Lia Buarque de Macedo Guimarães

Universidade Federal do Rio Grande do Sul - UFRGS

Porto Alegre, RS, Brasil

E-mail: lia@producao.ufrgs.br 